\title{
Study on the Correlation of Vibration Properties and Crack Index in the Health Assessment of Tunnel Lining
}

\author{
Xuezhen Wu, ${ }^{1,2}$ Yujing Jiang, ${ }^{1,2}$ Kusaba Masaya, ${ }^{1}$ \\ Tetsuya Taniguchi, ${ }^{3}$ and Takahide Yamato ${ }^{4}$ \\ ${ }^{1}$ Graduate School of Engineering, Nagasaki University, Nagasaki 852-8521, Japan \\ ${ }^{2}$ State Key Laboratory of Mining Disaster Prevention and Control Co-Founded by Shandong Province and the Ministry of \\ Science and Technology, Shandong University of Science and Technology, Qingdao 266590, China \\ ${ }^{3}$ West Nippon Expressway Engineering Kyushu Co., Ltd., Fukuoka 810-0073, Japan \\ ${ }^{4}$ West Nippon Expressway Co., Ltd., Nagasaki 854-0063, Japan
}

Correspondence should be addressed to Yujing Jiang; jiang@nagasaki-u.ac.jp

Received 20 February 2017; Accepted 2 April 2017; Published 18 April 2017

Academic Editor: Tai Thai

Copyright (C) 2017 Xuezhen Wu et al. This is an open access article distributed under the Creative Commons Attribution License, which permits unrestricted use, distribution, and reproduction in any medium, provided the original work is properly cited.

\begin{abstract}
This paper examines the correlation of vibration properties and crack index of tunnel lining in evaluating risk of collapsing. The visual inspection method, which was widely used, was not reliable enough as the stability of tunnel lining was influenced by the voids and the cracks that were invisible. A new method for the health assessment of tunnel lining was proposed, which can evaluate the whole structural condition according to the vibration properties of tunnel lining. A series of field tests were conducted to evaluate the validity of this new method and to make a comparative analysis with the visual inspection test results. The resultant average spectrum (RAS) of tunnel lining was identified according to the acceleration data of ambient vibration test of Hidake Tunnel in Japan. The tunnel lining crack index (TCI) was also obtained by digital visual inspection test. The correlation between the vibration characteristics and the crack index of tunnel lining was confirmed. However, the voids and the cracks on the inside of the lining were neglected in visual inspection test, which could pose a serious threat to tunnel safety. The vibration measurements by seismometer are an effective way to evaluate the global stability of tunnel lining.
\end{abstract}

\section{Introduction}

The tunnels play an important role in the transportation projects. A large number of tunnels have been in service for decades all over the world, and they were mainly supported by concrete lining [1]. The persistent ageing and earthquake cause many problems to the concrete lining, such as cracking, corrosion, and seepage $[2,3]$. The deterioration and damage of concrete lining decrease the integrity of tunnels and subsequently affect the safety of vehicle and pedestrian [4].

The mechanical stability of a tunnel is influenced greatly by the cracks in the lining. Generally, stability assessment of tunnel lining is performed by visual inspection of the cracks [5]. However, it is questionable to predict tunnel lining failure only by the crack at the lining surface. The uncertainty relationship between the crack characteristics and the instability of tunnel lining require more alternative assessment methods. Some different methods, such as the magnetic method, ultrasonic method, and ground penetrating radar method, were proposed $[6,7]$. However, only local information of the structure can be measured in these techniques. A lot of time and cost are required to estimate the overall tunnel [8].

Recently, evaluating the structural condition according to the vibration properties of tunnel lining has attracted the attention of many researchers [9-13]. However, these attempts have encountered great difficulties as the forced vibration test was adopted. The forced vibration test is not suitable for the damage detection of large-scale structures, where the huge reaction mass shakers are necessary [14]. A more effective approach was proposed by the authors [15], which evaluated condition of tunnel lining by the ambient vibration test. This method was proposed based on the basic 


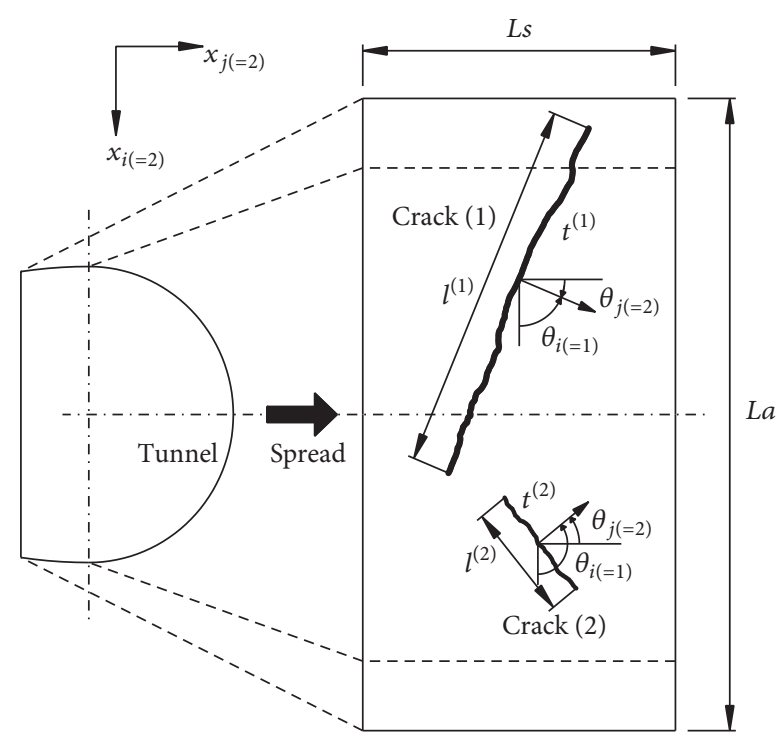

Figure 1: Conceptual diagram of tunnel lining crack index (TCI).

physical principle: the stability of the tunnel lining is closely related to its strength and stiffness, and the strength and stiffness are closely related to the vibration properties. The damage of the tunnel lining will cause changes in the strength and stiffness, subsequently affecting the vibration characteristics.

The vibration measurements by seismometer are a promising way to evaluate the global stability of tunnel lining. However, the field test data was limited. Particularly, the data that can be compared with the conventional test method was not available. To evaluate the stability of tunnel lining more precisely and to evaluate the validity of this new method, it is meaningful to study the quantitative correlation between the crack index and the vibration characteristics.

\section{Research Background}

Originally, the stability of aged tunnel linings was mainly evaluated based on the visual inspection in Japan [5]. But the evaluation standard was qualitative, and the results depended on the experience of engineer. As a solution of this problem, the tunnel lining crack index (TCI) was proposed to evaluate the severity of cracks quantitatively $[16,17]$. The conceptual diagram of TCI was shown in Figure 1. One span of the tunnel shown in the left side of the figure was spread out to a flat surface as shown in the right side. The basic formula of TCI is shown in

$$
F_{i j}=\frac{1}{A} \sum_{k=1}^{n}\left(t^{(k)}\right)^{\alpha}\left(l^{(k)}\right)^{\beta} \cos \theta_{i}^{(k)} \cos \theta_{j}^{(k)},
$$

where $A$ is the total area of the lining; $n$ is the number of cracks. $t$ and $l$ donate the width and length of crack $k . \theta_{i}$ and $\theta_{j}$ donate the angles formed by the normal vector of the crack with the $x_{i}$-axis and $x_{j}$-axis. $\alpha$ and $\beta$ donate the weighting coefficients of crack width and length.
$F_{11}$ and $F_{22}$ obtained by (1) indicated the longitudinal component and the transverse component of the TCI, respectively. The crack index $F_{0}$ was expressed as the sum of longitudinal and transverse components as shown in (2). Associating (1) and (2), the crack index $F_{0}$ can be derived as (3) in the following:

$$
\begin{aligned}
& F_{0}=F_{11}+F_{22}, \\
& F_{0}=\frac{1}{A} \sum_{k=1}^{n}\left(t^{(k)}\right)^{\alpha}\left(l^{(k)}\right)^{\beta} .
\end{aligned}
$$

Based on a line sensor camera and crack capture procedure, the TCI can be digitally evaluated. The width, length, and direction of cracks were considered. It was an objective evaluation method without depending on the technical force of the inspection engineer. This method has been widely used in the soundness evaluation of tunnel lining in Japan.

However, the relevance of tunnel lining stability and the visible cracks on the surface of the lining was questionable. The stability of tunnel lining was also influenced by the voids and the cracks that were invisible. In addition, some approximations have to be used in the calculation of crack index. For example, the cracks were not always straight lines, but they were divided into small segments and considered as straight lines to simplify the calculation. The uncertainty relevance of TCI and tunnel lining state called for a different method to estimate the stability of tunnel lining.

\section{Health Assessment of Tunnel Lining Based on the Ambient Vibration Test}

As one type of ambient vibration, microtremor has attracted more and more attentions in the health assessment of concrete structures recently $[18,19]$. Microtremor is low amplitude ambient vibration of the ground caused by natural phenomena such as wind, ocean waves, and volcano, as well as human activates such as movement of machinery in factories and motor cars.

Actually, all the objects are in vibration all the time. According to the basic vibration model, the natural frequency was basically expressed as (1). The damage of the objects always results in a localized reduction of the stiffness. Through analyzing the microtremor data, some useful properties of a structure, such as the amplitude and natural frequency, can be obtained

$$
\omega^{2}=\frac{k}{M}
$$

The ambient vibration test has been successfully used in many types of structures, including buildings and bridges [20-22]. However, few attentions have been focused on the damage identification of tunnel linings, as they were embedded in rock mass and the vibration behavior was very complex. The vibration behavior of tunnel lining was influenced not only by its overall stiffness, but also by the interaction of surrounding rock mass and structure.

The tunnel lining can be treated as a cylindrical shell of which the thickness is much smaller than the other 


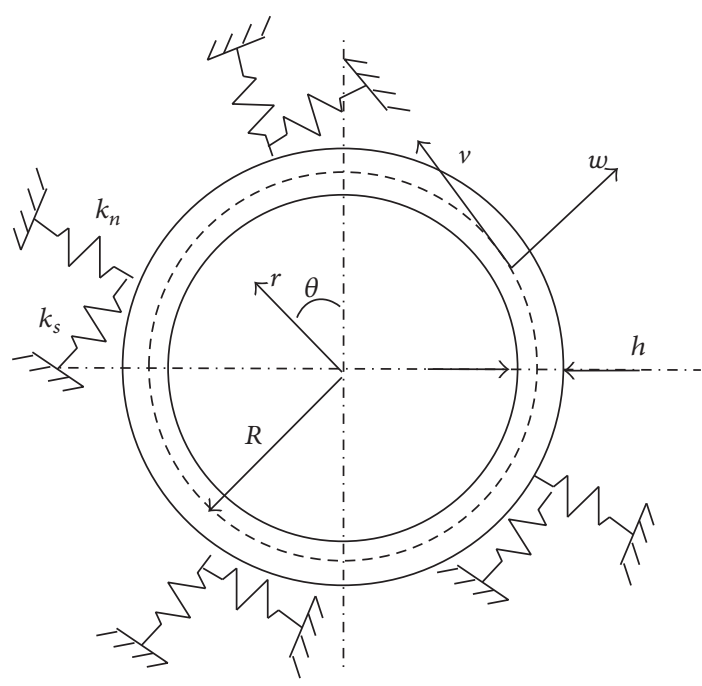

FIgURE 2: The schematic of a circular cylindrical shell.

dimensions. The thin shell theory can be used for the analysis of tunnel lining vibration. The vibration properties of thin elastic shell have been studied by many researchers $[23,24]$. The Donnell-Mushtari shell theory is relatively simple and adopted to analyze the vibration characters of tunnel lining. The contacts of rock mass and concrete lining were considered as an elastic boundary which can be represented by the distributed springs as shown in Figure 2.

The deformations mainly exist in the cross section. Meanwhile, the boundary condition is considered as the same along the axial direction. The displacement functions illustrated in Figure 2 can be represented as follows:

$$
\begin{aligned}
& u=0, \\
& v=v(\theta), \\
& w=w(\theta) .
\end{aligned}
$$

The equations governing the vibrations in a plane strain model were expressed as [25]:

$$
\begin{aligned}
& \frac{\partial^{2} v}{\partial \theta^{2}}+\frac{\partial w}{\partial \theta}+b\left(\frac{\partial^{2} v}{\partial \theta^{2}}-\frac{\partial^{3} w}{\partial \theta^{3}}\right)-\frac{R^{2} k_{s} v}{K} \\
&= \frac{R^{2}}{K}\left(\rho h \frac{\partial^{2} v}{\partial t^{2}}\right) \\
& \frac{\partial v}{\partial \theta}+w-b\left(\frac{\partial^{3} v}{\partial \theta^{3}}-\frac{\partial^{4} w}{\partial \theta^{4}}\right)+\frac{R^{2} k_{n} w}{K} \\
&=\frac{R^{2}}{K}\left(-\rho h \frac{\partial^{2} w}{\partial t^{2}}\right)
\end{aligned}
$$

where $K=E h /\left(1-\mu^{2}\right), E$ is Young's modulus of elasticity and $\mu$ is Poisson's ratio; $b=h^{2} / 12 R^{2}, h$ is the shell's thickness and $R$ is the radius of the middle surface of the shell; $v$ and $w$ are the orthogonal components of displacement of the shell; $\rho$ is density of the shell; $k_{n}$ and $k_{s}$ are the normal stiffness

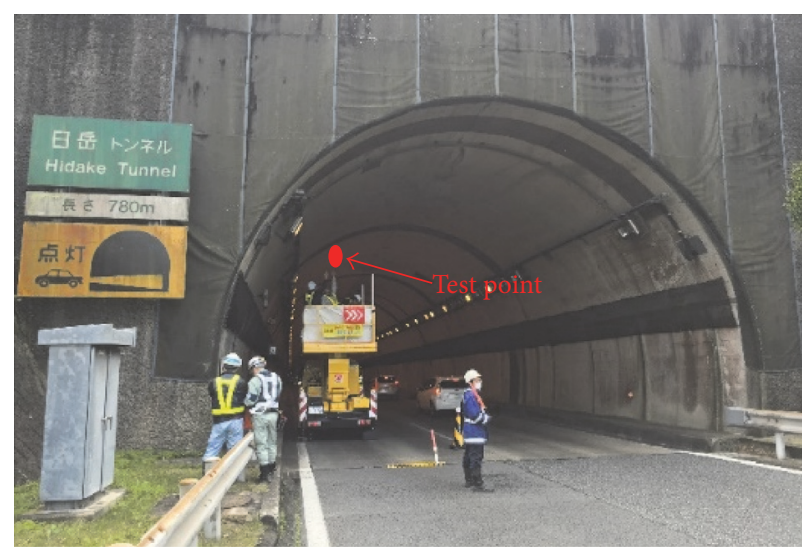

FIgure 3: Ambient vibration test of Hidake Tunnel in Japan.

and shear stiffness of the concrete-rock interfaces. Using the Laplace transformation, the frequency factor of tunnel lining can be obtained:

$$
\begin{aligned}
& \frac{\rho h R^{2}}{K} \omega^{2}=1+\frac{R^{2}}{K} k_{n} \quad(n=0), \\
& \frac{\rho h R^{2}}{K} \omega^{2}=\frac{1}{2}\left(1+\frac{R^{2}}{K} k_{n}+\frac{R^{2}}{K} k_{s}+n^{2}+b n^{4}\right) \\
& \quad \frac{ \pm(1 / 2) \sqrt{\left(1+\left(R^{2} / K\right) k_{n}+\left(R^{2} / K\right) k_{s}+n^{2}+b n^{4}\right)^{2}}}{+4 n^{2}-4\left(n^{2}+\left(R^{2} / K\right) k_{s}\right)\left(1+b^{4}+\left(R^{2} / K\right) k_{n}\right)} \\
& \quad(n \neq 0) .
\end{aligned}
$$

These theoretical studies laid the foundation for tunnel lining health assessment based on vibration properties. The main factors that affect the vibration of the tunnel lining include Young's modulus, Poisson's ratio, and the thickness, the radius, and the density of the lining. The normal stiffness and shear stiffness of the concrete-rock interfaces will also affect the tunnel vibration characteristics.

\section{A Case Study of Hidake Tunnel in Japan}

To evaluate the validity of this new method and to make a comparative analysis with the visual inspection test results, a series of field tests were conducted at Hidake Tunnel in Japan.

4.1. Basic Condition of Hidake Tunnel. The Hidake Tunnel (as shown in Figure 3) located in Nagasaki Prefecture, Japan, was taken as an example to study the quantitative correlation between the crack characteristics and the vibration characteristics. The tunnel was constructed in 1982 with the polingboard method. The tunnel length is $780 \mathrm{~m}$, and the maximum depth is $25 \mathrm{~m}$. The thickness of the concrete lining is $0.7 \mathrm{~m}$ at a part of the tunnel and $0.55 \mathrm{~m}$ at the other part. The surrounding rocks are sandstone, sand tuff, lapilli tuff, basalt, tuff breccia, and lapilli tuff in different segments.

Some defects such as cracks and seepages began appearing in the concrete lining after twenty years of service, due to the alteration of geological conditions and the deterioration 
TABLE 1: The basic conditions of the concrete lining for ten studied spans.

\begin{tabular}{lcccc}
\hline $\begin{array}{l}\text { Span } \\
\text { number }\end{array}$ & Lining thickness & Inverted arch & Buried depth & Surrounding rock type \\
\hline 1 & $0.70 \mathrm{~m}$ & Yes & $3 \mathrm{~m}$ & Sandstone \\
12 & $0.55 \mathrm{~m}$ & No & $25 \mathrm{~m}$ & Sand tuff \\
16 & $0.55 \mathrm{~m}$ & No & $25 \mathrm{~m}$ & Sand tuff \\
18 & $0.55 \mathrm{~m}$ & No & $25 \mathrm{~m}$ & Sand tuff \\
20 & $0.55 \mathrm{~m}$ & No & $25 \mathrm{~m}$ & Lapilli tuff \\
35 & $0.70 \mathrm{~m}$ & No & $23 \mathrm{~m}$ & Basalt \\
42 & $0.55 \mathrm{~m}$ & No & $23 \mathrm{~m}$ & Basalt \\
49 & $0.55 \mathrm{~m}$ & No & $23 \mathrm{~m}$ & Tuff breccia \\
58 & $0.70 \mathrm{~m}$ & No & $0 \mathrm{~m}$ & Lapilli tuff \\
65 & $0.70 \mathrm{~m}$ & Yes & Lapilli tuff \\
\hline
\end{tabular}

of lining concrete. The tunnel inspection was carried out in detail in 2013 and some defects in the tunnel lining were confirmed. The tunnel was affected by the Kumamoto earthquakes, including a magnitude 7.0 main shock, on April 16, 2016. The government decided to carry out a large-scale renovation to prevent the possible collapse of tunnel lining. The digital visual inspection and ambient vibration test were conducted before the renovation to assess the extent of damage to the tunnel. There are a total of 65 spans in Hidake Tunnel, and ten typical spans were selected in this study. The basic condition of the ten studied spans was shown in Table 1.

4.2. Digital Visual Inspection Test. The tunnel lining crack index was calculated to evaluate the distribution density of the cracks on the lining surface. The process of extracting cracks was shown in Figure 4. The continuous crack images as shown in Figure 4(a) were obtained by a photographing vehicle equipped with line sensor camera. The round surface was automatically spread out to a flat surface. The cracks were extracted from the images as shown in Figures 4(b) and 4(c) by a crack identification program. The cracks on tunnel lining surface were extracted for all the 65 spans in Hidake Tunnel, and the results of ten studied spans were shown in Figure 5. In Figure 5, the width of the cracks was shown through different colors. The black line means the cracks width is less than $0.5 \mathrm{~mm}$. The light blue line means the cracks width is between $0.5 \mathrm{~mm}$ and $1 \mathrm{~mm}$. The green line means the cracks width is between $1 \mathrm{~mm}$ and $2 \mathrm{~mm}$. The red line means the cracks width is large than $2 \mathrm{~mm}$.

The TCI for different spans was calculated and shown in Table 2. Many cracks were found in spans 1, 42, 49, 58, and 65. Especially in spans 49 and 58, some wide cracks were found, which would increase the risk of tunnel lining collapse greatly. There were a large number of small cracks in span 65, but no wide cracks were found. Few cracks were found in spans 12, $16,18,20$, and 35 , which may mean a smaller risk of lining collapse.

As described in Section 2, the relevance of tunnel lining stability and the visible cracks on the surface of the lining was questionable. So, the ambient vibration test was conducted to check the vibration properties of tunnel lining.

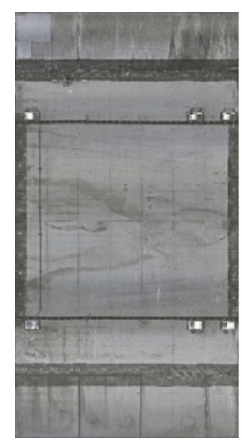

(a)

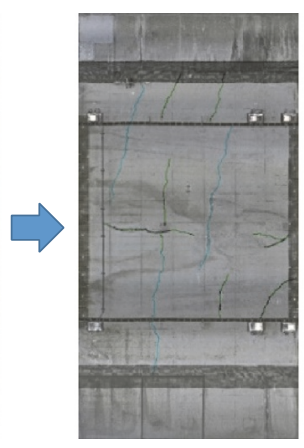

(b)

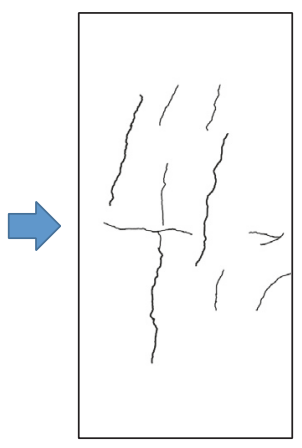

(c)
FIGURE 4: Extraction of cracks on tunnel lining surface: (a) unfolded crack image; (b) identification of cracks; (c) extraction of cracks.

TABLE 2: Tunnel-lining crack index of the ten studied spans.

\begin{tabular}{lccc}
\hline Span number & $F_{11}\left(10^{-5}\right)$ & $F_{22}\left(10^{-5}\right)$ & $F_{0}\left(10^{-5}\right)$ \\
\hline 1 & 4.644 & 12.709 & 17.353 \\
12 & 1.964 & 1.969 & 3.933 \\
16 & 1.837 & 0.203 & 2.040 \\
18 & 1.179 & 1.466 & 2.645 \\
20 & 3.885 & 0.278 & 4.163 \\
35 & 0.321 & 1.569 & 1.890 \\
42 & 3.470 & 6.580 & 10.050 \\
49 & 19.000 & 21.281 & 40.281 \\
58 & 20.937 & 9.705 & 30.642 \\
65 & 13.995 & 12.122 & 26.117 \\
\hline
\end{tabular}

\subsection{The Vibration Properties by Ambient Vibration Test}

4.3.1. Measurement System. The microtremors were measured at the ten studied spans of Hidake Tunnel. As the vibration amplitude of the tunnel lining mainly caused by traffic is fairly small, usually about hundreds of mgals $\left(\mathrm{cm} / \mathrm{s}^{2}\right)$, high accuracy accelerometers with a resolution of $1 \mathrm{mgal}$ were utilized in microtremor measurements. The measurement system consists of three servo accelerometers, controller, data recorder, and computer as shown in Figure 6. 


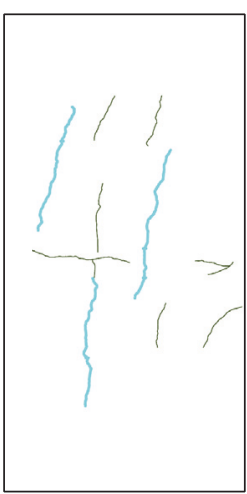

Span 1

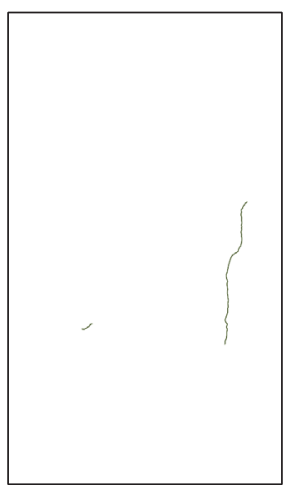

Span 35

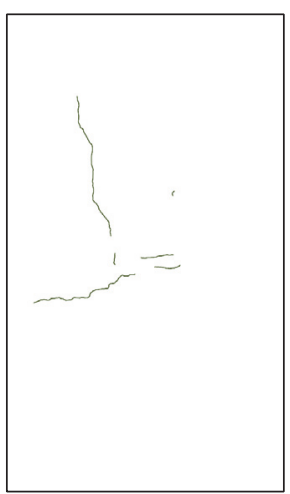

Span 12

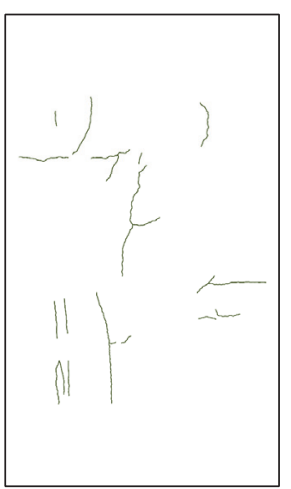

Span 42

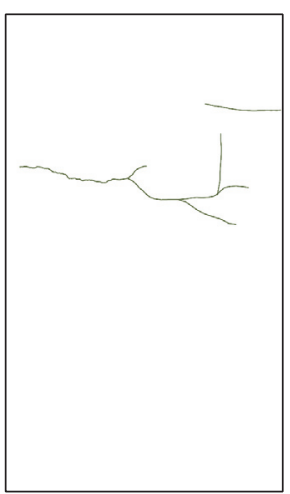

Span 16

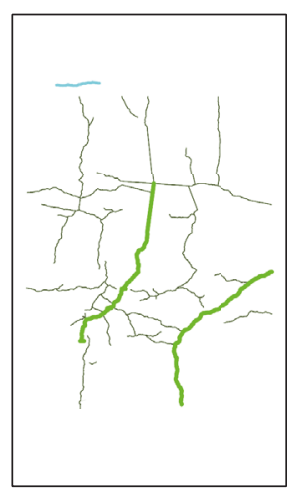

Span 49

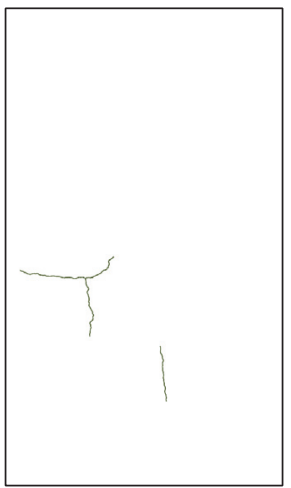

Span 18

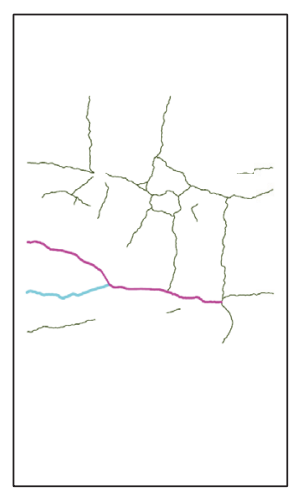

Span 58

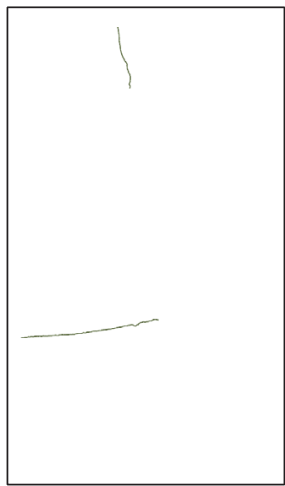

Span 20

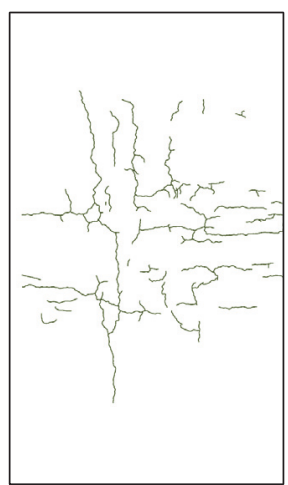

Span 65

FIgURE 5: Cracks distribution on tunnel lining surface for ten studied spans.
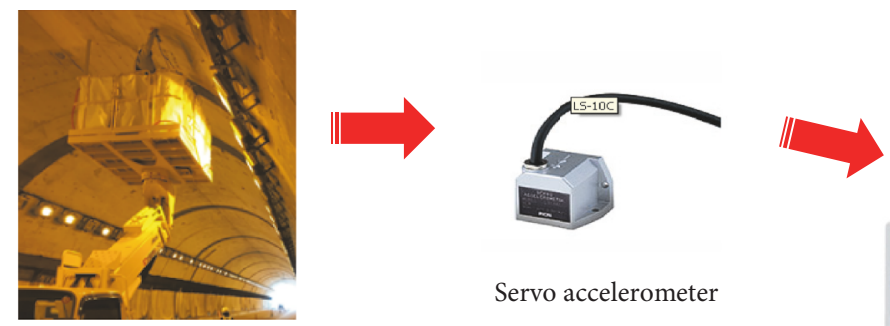

Servo accelerometer
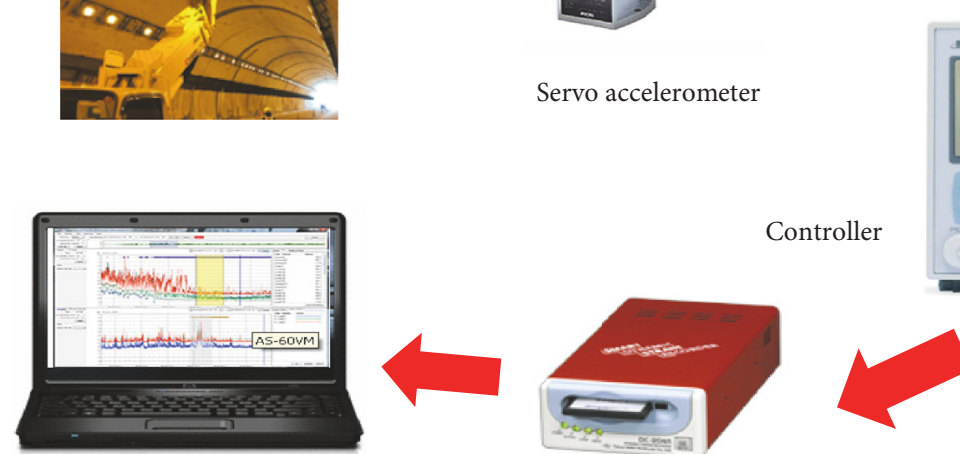

Computer

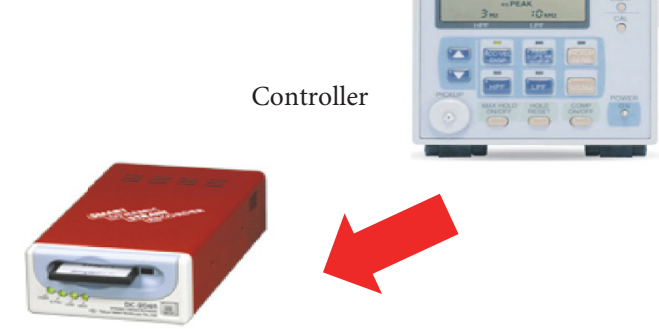

Data recorder

FIGURE 6: The microtremor measurement system of tunnel lining.

As the vibration properties of tunnel lining can reflect its overall stiffness, only one measuring point on the arch was selected for one span during the limited measuring time. The position of the test point was shown in Figure 3. As the data record must be sufficiently long in order to reduce the influence of interfering signals, the measurements last for 180 seconds with an interval of 0.001 seconds.

4.3.2. Ambient Vibration Test Results. A part of the measured acceleration of tunnel lining in span 1 was shown in Figure 7. 


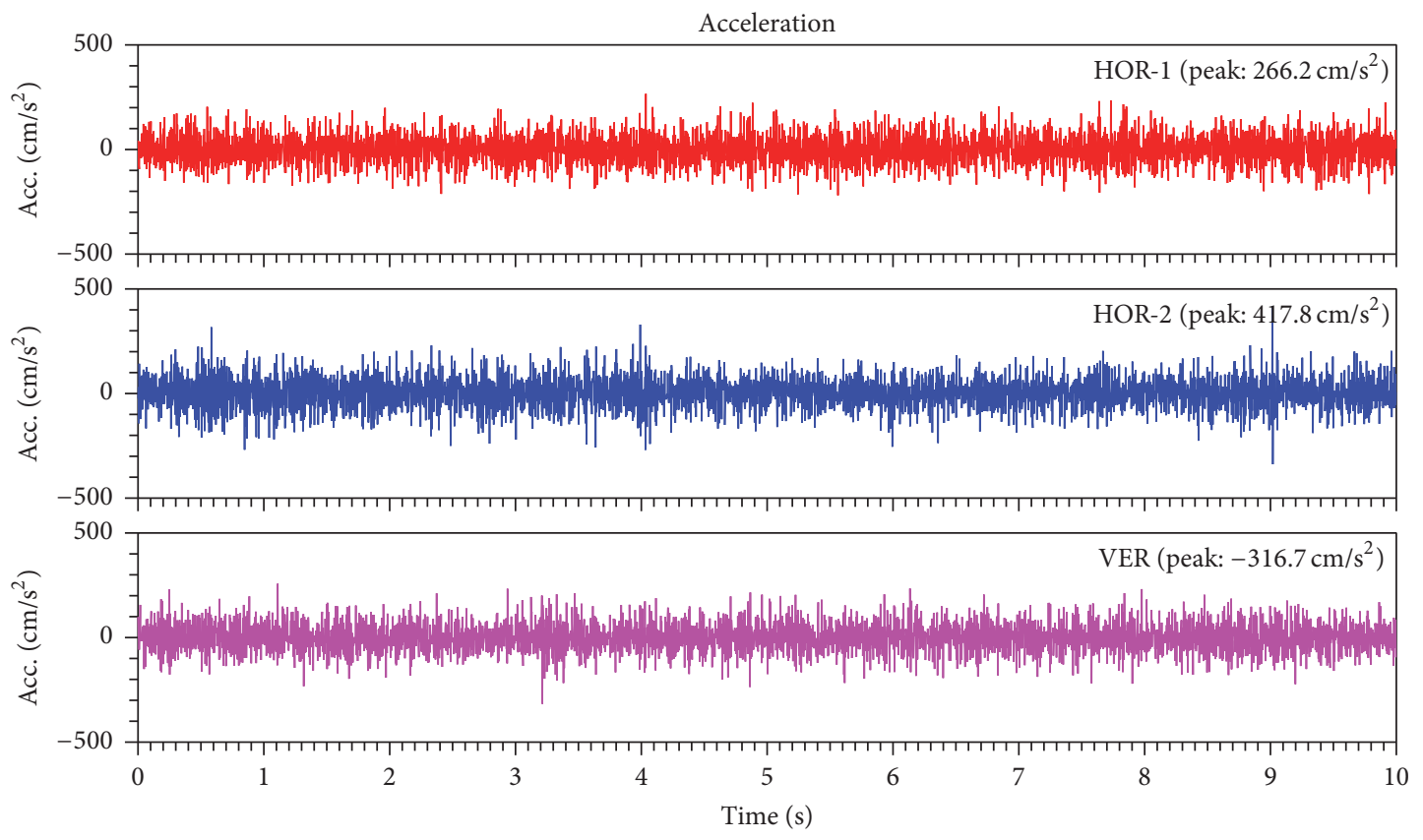

Figure 7: A part of the measured microtremor in span 1.

The HOR-1 in the figure means the acceleration in tunnel axial direction. The HOR-2 means the acceleration in tunnel circumference direction. The VER means the direction perpendicular to the tunnel lining surface.

The results were easier to analyze in the frequency domain, and they can be obtained by Fourier transform from the time domain signal. In this study, a steady waveform of 10 seconds was selected for each measuring point. The interfering signals which may be induced by the heavy traffic were not used. The Fourier spectrum of vibration for ten studied spans was obtained, and some of the typical ones were shown in Figure 8. In the calculation, the width of Parzen window was adopted as $1 \mathrm{~Hz}$ to smooth the curve.

As shown in Figure 8, the microtremors of tunnel lining have a high noise ratio, and the frequency was distributed over a wide range, which made it difficult to identify the natural frequency exactly. Therefore, the average vibration amplitude over the spectrum was used to compare results for different spans. The average spectrum in three directions within the frequency domain of $50 \sim 200 \mathrm{~Hz}$ was defined as $S_{x}$, $S_{y}$, and $S_{z}$, respectively. The resultant average spectrum (RAS) can be obtained as (8). The resultant average spectrum of the concrete lining was shown in Table 3

$$
\mathrm{RAS}=\sqrt{S_{x}^{2}+S_{y}^{2}+S_{z}^{2}}
$$

The values of RAS range from 12.757 to 14.393 . They were mainly influenced by the stiffness of concrete lining, stiffness of lining-rock joint, surrounding rock types, and lining thickness. The values of RAS were supposed to be related to the stability of tunnel lining. According to the theoretical results, a larger stiffness of concrete lining will result in a smaller value of RAS. The stiffness of lining-rock joint has a similar
TABLE 3: The resultant average spectrum (RAS) of the concrete lining.

\begin{tabular}{lcccc}
\hline Span number & $S_{x}$ & $S_{y}$ & $S_{z}$ & RAS \\
\hline 1 & 7.566 & 8.591 & 7.525 & 13.699 \\
12 & 7.435 & 7.329 & 7.488 & 12.847 \\
16 & 7.420 & 7.071 & 7.612 & 12.767 \\
18 & 7.470 & 7.586 & 7.904 & 13.260 \\
20 & 7.480 & 7.484 & 8.478 & 13.559 \\
35 & 7.389 & 7.213 & 7.681 & 12.869 \\
42 & 7.642 & 7.238 & 7.209 & 12.757 \\
49 & 7.657 & 7.578 & 8.441 & 13.686 \\
58 & 7.983 & 8.771 & 7.952 & 14.279 \\
65 & 7.927 & 8.384 & 8.605 & 14.393 \\
\hline
\end{tabular}

influence. When the surrounding rock is hard rock, the value of RAS will be relatively small.

\section{Correlation between the Crack Index and the Vibration Characteristics}

The correlation between the crack index and the vibration characteristics was discussed in this part. According to the crack index TCI $\left(F_{0}\right)$ shown in Table 2 and vibration characteristics RAS shown in Table 3, their correlation was presented in Figure 9. The results by two different methods have shown a linear relationship with a correlation coefficient of 0.5538 . The correlation coefficient is relatively small. It is because that the vibration characteristics were influenced by many factors, and the crack index is only one of them. Therefore, the correlation between the vibration characteristics and the crack index of tunnel lining was confirmed. 

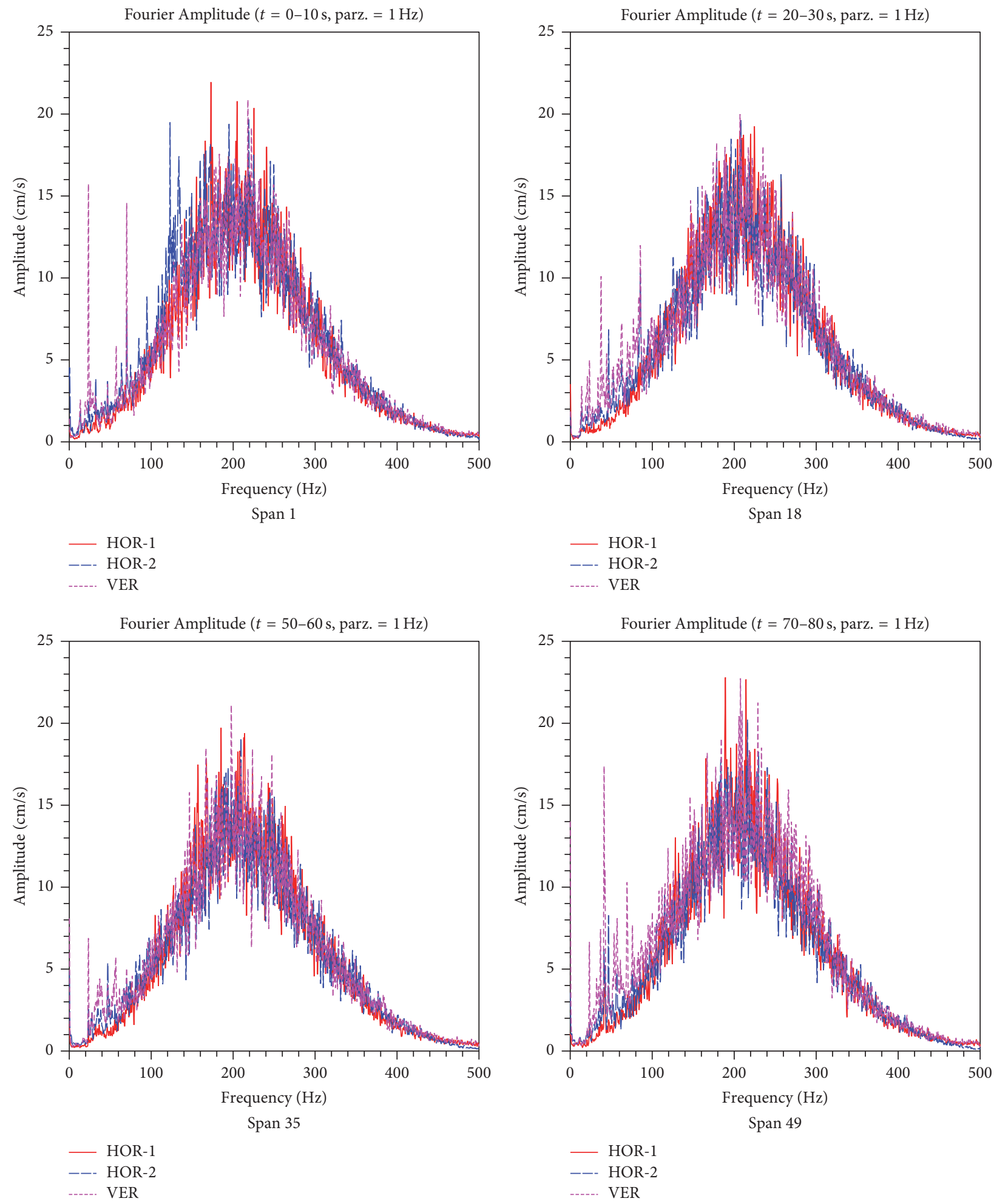

FIGURE 8: The velocity spectrum of vibration for spans 1, 18, 35, and 49.

The concrete lining of spans $1,49,58$, and 65 was located in the unhealthy area by both methods. Spans $12,16,35$, and 42 were located in the healthy area by both methods. For these test points, the results by the two different methods were consistent with each other. However, the result of span 20 was quite different. It was located in the healthy area by the conventional visual inspection test. But the ambient vibration test results showed that the value of RAS was quite large and located in the unhealthy area. Probably, the vibration characteristics were influenced by the voids and the cracks 


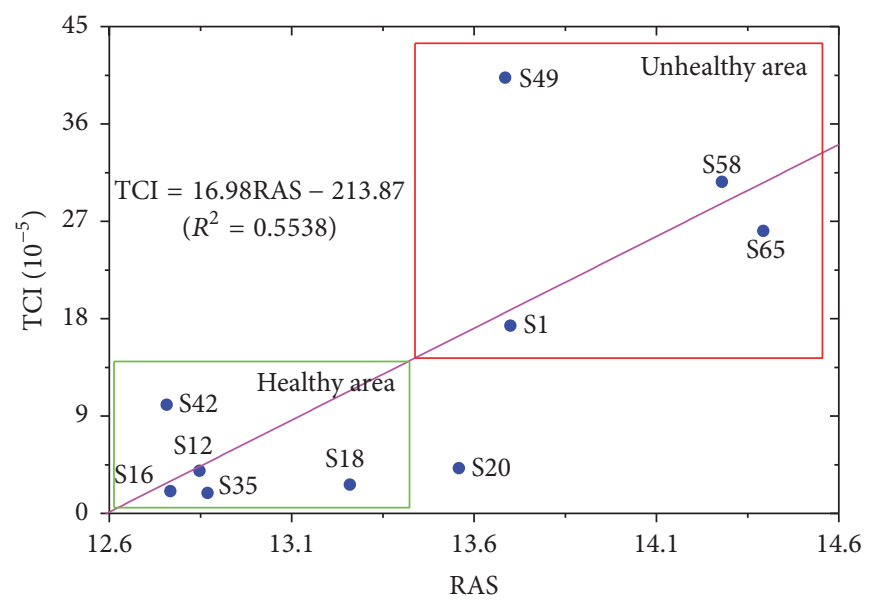

FIGURE 9: The correlation between the crack index and the vibration characteristics.

on the inside of the lining that were invisible. This conjecture was confirmed during the grouting process, as significantly more cement was used in span 20 than other healthy spans. Such neglected defects in conventional visual inspection test would pose a serious threat to tunnel safety.

Considering the basic conditions of the tunnel in Table 1, the factors that influence the vibration characteristics of the tunnel lining were discussed. Compared with the influence of crack index, the influence of lining thickness on the vibration characteristics was not significant. No obvious difference was found for both kinds of thickness of the lining. According to theoretical analysis, the vibration characteristics of tunnel lining should be affected by the thickness, but it was covered by other factors in these tests, especially the cracks in the lining.

The buried depth seemed to have an impact on the vibration of tunnel lining. The RAS values of spans 1 and 65 that had small depth were both relatively large. Obviously, a small load from the overlying rock mass will result in a large RAS value. On the other hand, these two spans were all at the ends of the tunnel, which may also affect the vibration characteristics. Inverted arches were used in spans 1 and 65. Generally speaking, the inverted arches will reduce the values of RAS. However, this phenomenon was not reflected in the test results, as the vibration of spans 1 and 65 was influenced by many other factors.

The surrounding rock types also affected the vibration characteristics of the tunnel lining. The hard surrounding rocks will result in small RAS values, which can be seen from the results of spans 35 and 42 . They were located in the basalt, which belong to hard rocks. Spans 20, 58, and 65, located in the lapilli tuff, were all estimated to be unhealthy by the ambient vibration test. These results were consistent with the numerical simulation results carried out by the authors [25].

The results suggested that the conventional visual inspection test, which evaluates the health status of tunnel lining only by the surface cracks, were unreliable. It is necessary to use a different method that can check the internal structure of the lining. The ambient vibration test is a promising method in the health assessment of tunnel lining, which can estimate the overall stiffness and stability. However, the vibration characteristics of tunnel lining were influenced by a large number of factors. More field test data and comparative study were needed to interpret the vibration test results. Nevertheless, the new health assessment method of tunnel lining is a good complement to the conventional visual inspection method.

\section{Conclusions}

The correlation of vibration properties and crack index of tunnel lining was studied in this paper. The development of health assessment methods for tunnel lining was first introduced. The visual inspection method was not reliable enough as the stability of tunnel lining was influenced by the voids and the cracks that were invisible.

A new method was proposed for the health assessment of tunnel lining, which evaluated the whole structural condition according to the vibration properties of tunnel lining. A series of field tests were conducted to evaluate the validity of this new method. The RAS of tunnel lining was identified according to the acceleration data of ambient vibration test of Hidake Tunnel. The TCI of studied spans in this tunnel was also obtained by digital visual inspection test.

The correlation between the crack index and the vibration characteristics was confirmed. However, some voids and cracks on the inside of the lining were neglected in conventional visual inspection test, which would pose a serious threat to tunnel safety. These defects were reflected in the new method. The significance of the new method is to identify the point where the vibration is abnormal and provide a basis for further internal testing. The vibration measurements by seismometer are an effective way to evaluate the global stability of tunnel lining. According to the ambient vibration test results, the influencing factors of tunnel lining safety were discussed in detail. A large number of field test data and detailed geological data were presented, which could be a reference for the comparative analysis in the future.

\section{Conflicts of Interest}

The authors declare that they have no conflicts of interest. 


\section{Acknowledgments}

This study is funded by the National Natural Science Foundation of China (no. 51379117 and no. 51479108).

\section{References}

[1] M. R. Soheyli, A. H. Akhaveissy, and S. M. Mirhosseini, "Largescale experimental and numerical study of blast acceleration created by close-in buried explosion on underground tunnel lining," Shock and Vibration, vol. 2016, Article ID 8918050, 9 pages, 2016.

[2] L. Malmgren, E. Nordlund, and S. Rolund, "Adhesion strength and shrinkage of shotcrete," Tunnelling and Underground Space Technology, vol. 20, no. 1, pp. 33-48, 2005.

[3] A. E. Aktan, F. N. Catbas, K. A. Grimmelsman, and C. J. Tsikos, "Issues in infrastructure health monitoring for management," Journal of Engineering Mechanics, vol. 126, no. 7, pp. 711-724, 2000.

[4] S. Bhalla, Y. W. Yang, J. Zhao, and C. K. Soh, "Structural health monitoring of underground facilities-technological issues and challenges," Tunnelling and Underground Space Technology, vol. 20, no. 5, pp. 487-500, 2005.

[5] Y. Hayashi, J. Imai, M. Yoshiduka, M. Suzuki, Y. Shigeta, and K. Nakagawa, "Restoration measures of tunnel experienced large deformation due to natural disaster," Doboku Gakkai Ronbunshu, no. 756, pp. 61-74, 2004.

[6] D. C. Jiles, "Review of magnetic methods for nondestructive evaluation," NDT International, vol. 21, no. 5, pp. 311-319, 1966.

[7] C. F. Poranski, E. C. Greenawald, and Y. S. Ham, "X-ray backscatter tomography: NDT potential and limitations," Materials Science Forum, vol. 210-213, no. 1, pp. 211-218, 1996.

[8] S. Park and S. Choi, "Development of methodology for estimating the effective properties of containment buildings," MidTerm Report KINS/HR-836, Korea Institute of Nuclear Safety, 2008.

[9] J. Lai, K. Wang, J. Qiu, F. Niu, J. Wang, and J. Chen, "Vibration response characteristics of the cross tunnel structure," Shock and Vibration, vol. 2016, Article ID 9524206, 16 pages, 2016.

[10] Q. Yu, C.-A. Tang, L. Li, G. Cheng, and L.-X. Tang, "Study on rockburst nucleation process of deep-buried tunnels based on microseismic monitoring," Shock and Vibration, vol. 2015, Article ID 685437, 17 pages, 2015.

[11] Y. Gao, Y. Jiang, and B. Li, "Estimation of effect of voids on frequency response of mountain tunnel lining based on microtremor method," Tunnelling and Underground Space Technology, vol. 42, pp. 184-194, 2014.

[12] L. Xuebin, "Study on free vibration analysis of circular cylindrical shells using wave propagation," Journal of Sound and Vibration, vol. 311, no. 3-5, pp. 667-682, 2008.

[13] F. Dai, B. Li, N. Xu, Y. Zhu, and P. Xiao, "Stability evaluation on surrounding rocks of underground powerhouse based on microseismic monitoring," Shock and Vibration, vol. 2015, Article ID 937181, 9 pages, 2015.

[14] B. Peeters, J. Maeck, and G. De Roeck, "Vibration-based damage detection in civil engineering: excitation sources and temperature effects," Smart Materials and Structures, vol. 10, no. 3, pp. 518-527, 2001.

[15] Y. Gao, Y. Jiang, and B. Li, "Voids delineation behind tunnel lining based on the vibration intensity of microtremors," Tunnelling and Underground Space Technology, vol. 51, pp. 338-345, 2016.
[16] Y. Shigeta, T. Tobita, K. Kamemura, M. Shinji, I. Yoshitake, and K. Nakagawa, "Propose of tunnel crack index (TCI) as an evaluation method for lining concrete," Doboku Gakkai Ronbunshuu, vol. 62, no. 4, pp. 628-632, 2006.

[17] T. Yamada, N. Sano, K. Baba, Y. Shigeta, I. Yoshitake, and K. Nishimura, "Evaluation method for soundness of lining concrete by tunnel-lining crack index," Doboku Gakkai Ronbunshuu F, vol. 65, no. 1, pp. 11-16, 2009.

[18] R. Tuladhar, F. Yamazaki, P. Warnitchai, and J. Saita, "Seismic microzonation of the greater Bangkok area using microtremor observations," Earthquake Engineering and Structural Dynamics, vol. 33, no. 2, pp. 211-225, 2004.

[19] J. Chatelain, B. Guillier, P. Guéguen, J. Fréchet, and J. Sarrault, "Ambient vibration recording for single-station, array and building studies made simple: CityShark II," International Journal of Geosciences, vol. 3, no. 6, pp. 1168-1175, 2012.

[20] F. Magalhães, Á. Cunha, and E. Caetano, "Online automatic identification of the modal parameters of a long span arch bridge," Mechanical Systems and Signal Processing, vol. 23, no. 2, pp. 316-329, 2009.

[21] C. Michel, P. Guéguen, and P.-Y. Bard, "Dynamic parameters of structures extracted from ambient vibration measurements: an aid for the seismic vulnerability assessment of existing buildings in moderate seismic hazard regions," Soil Dynamics and Earthquake Engineering, vol. 28, no. 8, pp. 593-604, 2008.

[22] E. N. B. S. Júlio, C. A. da Silva Rebelo, and D. A. S. G. Dias-daCosta, "Structural assessment of the tower of the University of Coimbra by modal identification," Engineering Structures, vol. 30, no. 12, pp. 3468-3477, 2008.

[23] L. Cremer, M. Heckl, and B. A. T. Petersson, "Structure-borne sound," Physics Today, vol. 28, p. 81, 1975.

[24] W. Soedel, Vibrations of Shells and Plates, CRC Press, 1981.

[25] Y. Jiang, Y. Gao, and X. Wu, “The nature frequency identification of tunnel lining based on the microtremor method," Underground Space, vol. 1, pp. 108-113, 2016. 


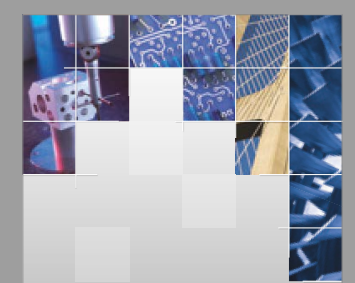

\section{Enfincering}
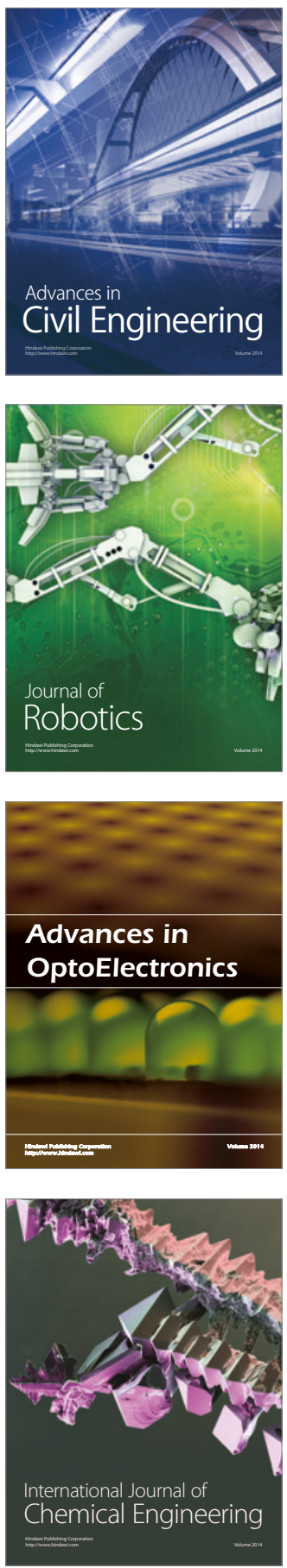

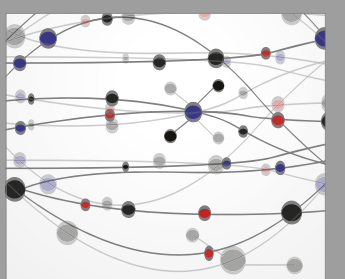

The Scientific World Journal

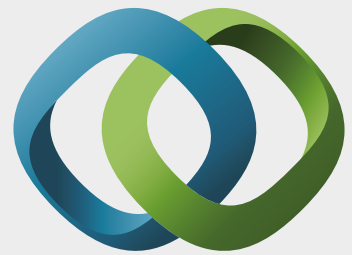

\section{Hindawi}

Submit your manuscripts at

https://www.hindawi.com
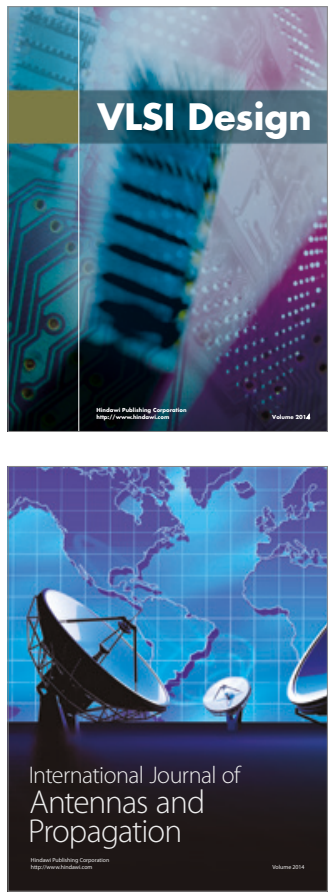

\section{Rotating}

Machinery
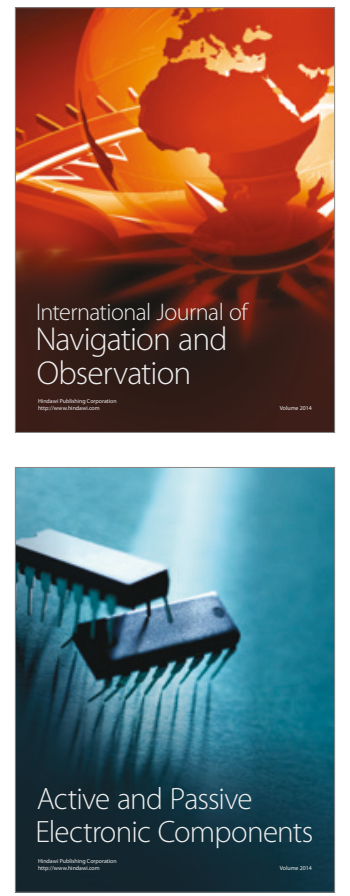
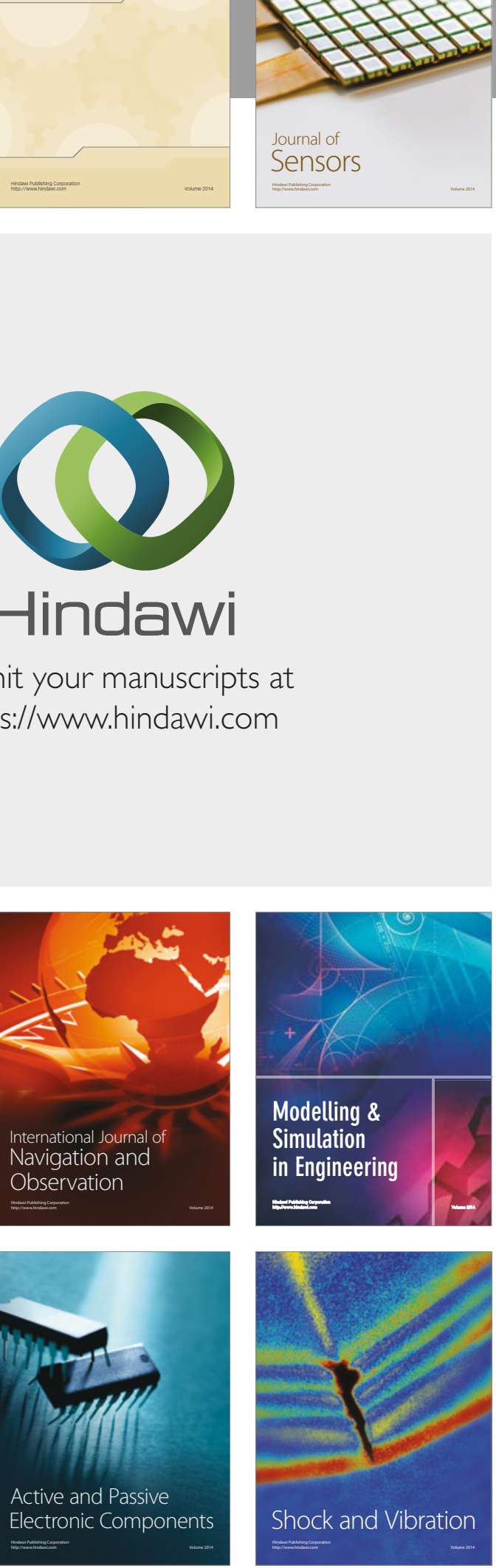
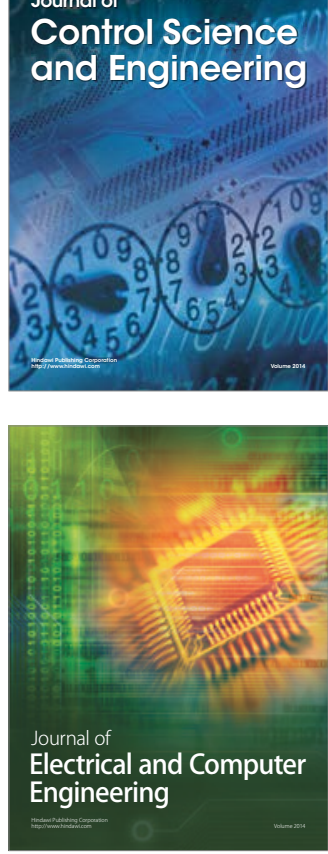

Distributed

Journal of

Control Science

and Engineering
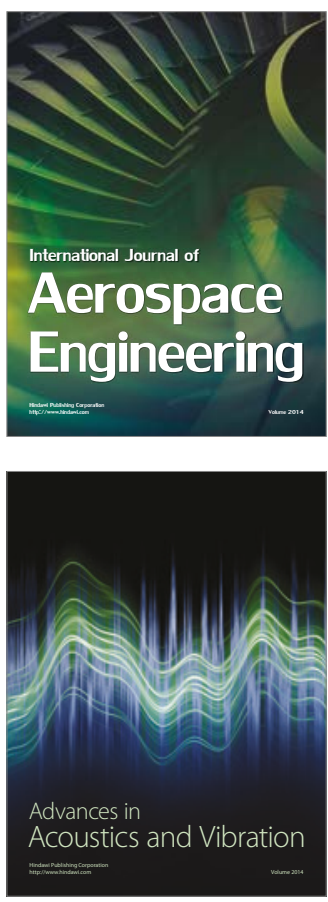

Sensor Networks 